\title{
Neoadjuvant chemotherapy for upper tract urothelial carcinoma
}

\author{
Do Kyung Kim ${ }^{1}$, Kang Su Cho ${ }^{2}$ \\ ${ }^{1}$ Department of Urology, Soonchunhyang University Seoul Hospital, Soonchunhyang University Medical College, Seoul, Republic of Korea; \\ ${ }^{2}$ Department of Urology, Gangnam Severance Hospital, Urological Science Institute, Yonsei University College of Medicine, Seoul, Republic of \\ Korea \\ Contributions: (I) Conception and design: All authors; (II) Administrative support: None; (III) Provision of study materials or patients: None; (IV) \\ Collection and assembly of data: None; (V) Data analysis and interpretation: None; (VI) Manuscript writing: All authors; (VII) Final approval of \\ manuscript: All authors. \\ Correspondence to: Kang Su Cho, MD, PhD. Departments of Urology, Gangnam Severance Hospital, Yonsei University College of Medicine, 211 \\ Eonju-ro, Gangnam-gu, Seoul, 06273, Republic of Korea. Email: kscho99@yuhs.ac.
}

\begin{abstract}
Upper tract urothelial carcinoma (UTUC) is a very uncommon disease that occupies for $<5 \%$ of all urothelial cancers. Radical nephroureterectomy (RNU) remains the standard-of-care for UTUC; however, when patients with locally advanced UTUC are treated with RNU only, the recurrence rate is high. Therefore, perioperative chemotherapy has been proposed given the high systemic recurrence rate. Moreover, there is growing evidence that neoadjuvant chemotherapy (NAC) plays an important role in the treatment of UTUC. Several studies and meta-analyses have reported the beneficial effect of NAC on survival outcomes and pathologic downstaging of patients with UTUC. However, the recommendation of NAC for UTUC is primarily based on level 1 evidence that demonstrated a beneficial effect on survival outcomes in patients with bladder cancer. The chemotherapy regimen for patients with UTUC is also based on that used for patients with bladder cancer. Nevertheless, the use of NAC for UTUC has some limitations, including the possibility of overtreatment. Therefore, selection criteria for NAC are needed, as are further trials to identify the most suitable patients and validate its use in daily clinical practice.
\end{abstract}

Keywords: Chemotherapy, Neoadjuvant, Nephroureterectomy, Upper tract urothelial carcinoma (UTUC)

Submitted Dec 23, 2019. Accepted for publication Feb 15, 2020.

doi: $10.21037 /$ tcr.2020.03.08

View this article at: http://dx.doi.org/10.21037/tcr.2020.03.08

\section{Introduction}

Upper tract urothelial carcinoma (UTUC) is a very uncommon disease that occupies for $<5 \%$ of all urothelial cancers (1). More than $60 \%$ of patients with UTUC have invasion at diagnosis, whereas only $20 \%$ of patients with UC of the bladder (UCB) have invasion at diagnosis (2). Invasive UTUC has poor prognosis, and as the T stage increases, the 5-year survival rate decreases; the median survival of patients with $\mathrm{T} 4$ disease is about 6 months $(3,4)$. Radical nephroureterectomy (RNU) with bladder cuff removal is a treatment of choice that can potentially UTUC in patients with normal contralateral kidneys, even if conservative treatment has a similar survival rate in patients with small and low-grade lesions or contraindications to radical surgery (4-6). However, in patients with locally advanced UTUC who are treated with RNU only, the recurrence rate is high (7). Therefore, perioperative chemotherapy may reduce the high systemic recurrence rate (8).

UTUC tumors are relatively sensitive to chemotherapy (9). Neoadjuvant chemotherapy (NAC) for UTUC may successfully eradicate micro-metastasis and result in pathological downstaging. Other reasons for NAC preference are cisplatin ineligibility after RNU and the chance of delivering higher doses of chemotherapy before surgery (3). Meanwhile, there is a potential risk of overtreatment without accurate pathological diagnosis. This may increase the perioperative morbidity owing to chemotherapy (10). However, there is increasing evidence that NAC plays an important role in the treatment of UTUC (11). 
Several recently published studies have examined treatment trends for UTUC using nationwide big data $(12,13)$. Browne et al. reported that the National Cancer Database displays a rise in chemotherapy for UTUC, chiefly in neoadjuvant settings, although NAC continues to comprise a small part of the whole chemotherapy (12). According to Cohen et al., the SEER-Medicare database shows that although NAC remains underused, its use has increased during the study period (13).

\section{Proven evidence in bladder cancer}

Chemotherapy for UTUC is primarily based on regimens that are used for UCB $(14,15)$. NAC for advanced UCB is recommended based on level 1 evidence that demonstrated a beneficial effect on survival outcomes $(16,17)$. The National Comprehensive Cancer Network guidelines recommend NAC, followed by radical cystectomy (category 1 recommendation) (18). In a Southwest Oncology Group randomized trial of 307 patients with muscle-invasive UCB, surgery alone was compared with three cycles of NAC (methotrexate, vinblastine, doxorubicin, and cisplatin) before surgery (19). The study reported that NAC increased the median survival among patients with locally advanced bladder cancer ( 77 vs. 46 months, $\mathrm{P}=0.06$ ) and increased the likelihood of eliminating residual cancer $(38 \% v s$. $15 \%, \mathrm{P}<0.001)$ with no obvious increment in treatmentrelated morbidity or mortality. In a meta-analysis of 11 trials with 3005 patients, cisplatin-based multi-agent NAC had a beneficial effect for the 5 -year overall survival (OS) and disease-free survival (DFS) rates $(5 \%$ and $9 \%$ absolute improvement, respectively) (14).

\section{Deterioration of renal function after RNU}

While RNU with bladder cuff removal is considered the standard treatment for advanced UTUC (4), an alternate approach may be needed due to patient comorbidities. Depending on tumor stage, grade, and patient factors, segmental ureterectomy or even endoscopic management of UTUC may be an option.

The majority of patients with UTUC who undergo surgery are not eligible for nephrotoxic cisplatin-based chemotherapy owing to a decrease in renal function after the surgical removal of the diseased kidney, ureter, and bladder cuff (10). Kaag et al. determined whether the ability to provide chemotherapy before RNU was affected by changes in kidney function after surgery (20). They reported that a significant decrease in renal function was observed after surgery, and these changes likely affected the eligibility for adjuvant cisplatin-based therapy. After RNU, renal function was significantly diminished, particularly in elderly patients. Several studies also reported a significant decrease in renal function after surgery (20-23). From this point of view, the neoadjuvant use of systemic chemotherapy should be strongly considered in advanced UTUC (20).

Experience with renal parenchymal tumors, which has proven that the nephron sparing surgery reduces the risk of developing chronic kidney disease, can likely apply to patients with UTUC $(24,25)$. This concept is very important for patients with UTUC because nearly $25 \%$ of patients have evidence of serious chronic kidney disease at diagnosis (26).

\section{Challenges with diagnosis and staging}

Diagnosis and staging of UTUC are usually achieved by a combination of image modalities, urine cytology, endoscopic observation and biopsy of tumor. A CT urography is the most commonly used imaging modality and the most common abnormal finding is a filling defect $(27,28)$. Endoscopic and/or percutaneous biopsies of UTUC for pathologic diagnosis, grading, and staging are technically difficult and often inaccurate. For this reason, it is difficult to develop an optimal treatment plan for UTUC patients.

There are several methods being developed to overcome the obstacles with clinical staging. One of them is the endoscopic luminal ultrasound, which can provide realtime evaluation of the depth of invasion of tumor. There are recent evidence that shows endoluminal ultrasound can improve the accuracy of clinical staging at the time of flexible ureteroscopy (29).

\section{Pathologic downstaging}

One of the primary rationales for NAC is the possibility of pathological downstaging of the tumor (30). In a phase 2 clinical trial at the MD Anderson Cancer Center, patients with locally advanced urothelial cancers were investigated for sequential NAC before surgery (31). In five patients with NAC followed RNU, three (60\%) eventually achieved pathologic downstaging to $\leq \mathrm{pT} 1 \mathrm{~N} 0$ disease. However, owing to the small number of patients in this trial, care should be taken before drawing conclusions regarding the positive effect of NAC in pathologic downstaging of 
UTUC. Matin et al. also reported that there was significant downstaging in the NAC group and that NAC was related to a $14 \%$ complete remission rate (32). Margulis et al. showed that 5 of 41 patients with UTUC who received NAC before surgery had no pathologic evidence of cancer (4). Moreover, we reported that the NAC group was 4.76 times more likely to have pathological $\mathrm{N}$ phase 0 than the surgery-only group in a previous meta-analysis (7).

\section{Improved oncological outcomes}

Several meta-analyses suggest the efficacy of NAC in patients with UTUC $(7,8,10,14,33)$. We summarize the characteristics and outcomes of previous meta-analyses in Table 1. The Advanced Bladder Cancer Meta-analysis Collaboration showed that a significant survival benefit associated with platinum-based chemotherapy for OS (HR 0.86, 95\% CI: 0.77-0.95, $\mathrm{P}=0.003$ ) and DFS (HR 0.78, 95\% CI: $0.71-0.86, \mathrm{P}<0.0001)(14)$. Leow et al. found a cancer-specific survival (CSS) benefit, i.e., a $59 \%$ decrease in the risk across two retrospective studies evaluating NAC (HR 0.41, 95\% CI, 0.22-0.76, P=0.005) (10). Yang et al. conducted a network meta-analysis to evaluate the prognosis of patients with UTUC who received different treatments with RNU (33). They reported that compared with the control, NAC was associated with a significant improvement in CSS. Gregg et al. found that NAC exhibited an OS benefit of a $64 \%$ decrease in risk across two retrospective studies (HR 0.36, 95\% CI: 0.19-0.69, $\mathrm{P}=0.002)(8)$. We evaluated the contemporary role of NAC for only patients with locally advanced UTUC (7) and showed that NAC increased the survival outcomes of locally advanced UTUC (OS, 57\%; CSS, 59\%; and PFS, 45\%). Despite the results of these studies, the level of evidence is low because few studies were included, and all the included studies used retrospective designs.

\section{Future directions}

The blockade of the programmed death-ligand 1 (PD-L1) -programmed death 1 (PD-1) pathway represents a new treatment for cancers with an extensive expression of PD-L1 and provides an OS benefit in several cancers (34-40). Nevertheless, there remains conflicting evidence on the prognostic significance of PD-L1 expression in UC. Balar et al. reported that atezolizumab, a blocking antibody targeting PD-L1, had a higher response rate in cases of UTUC than in those of UCB in a clinical trial of first-line

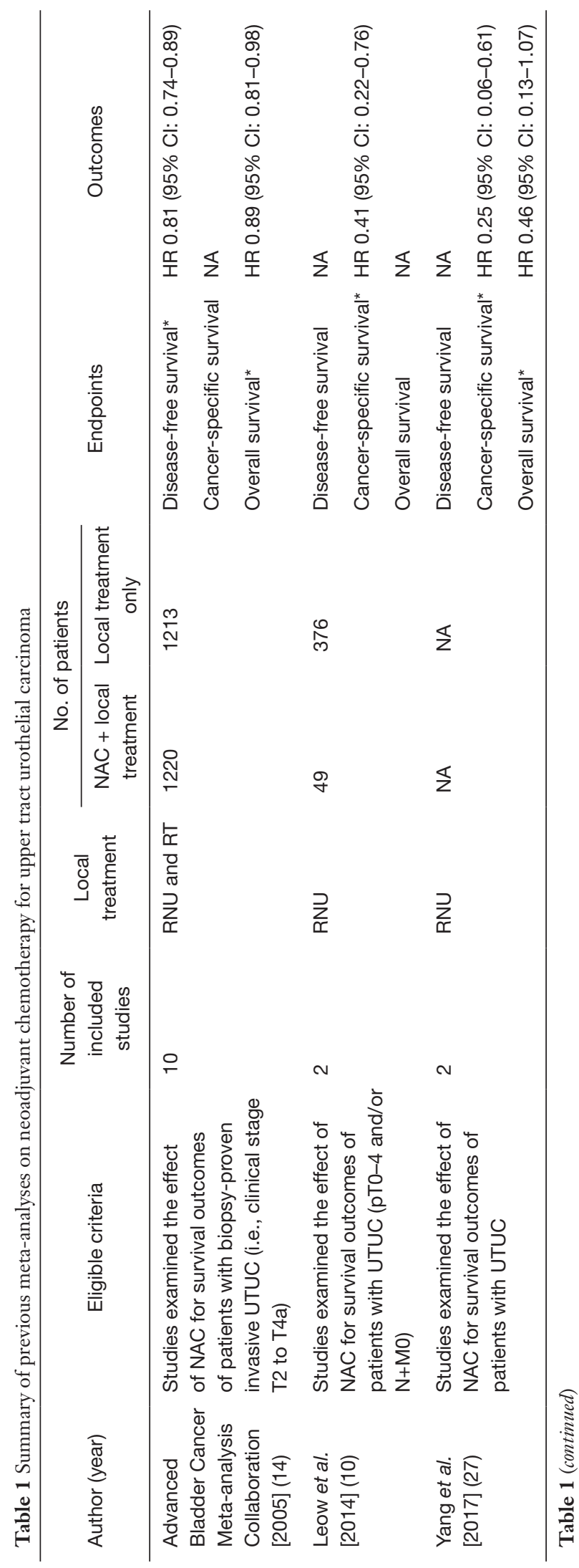




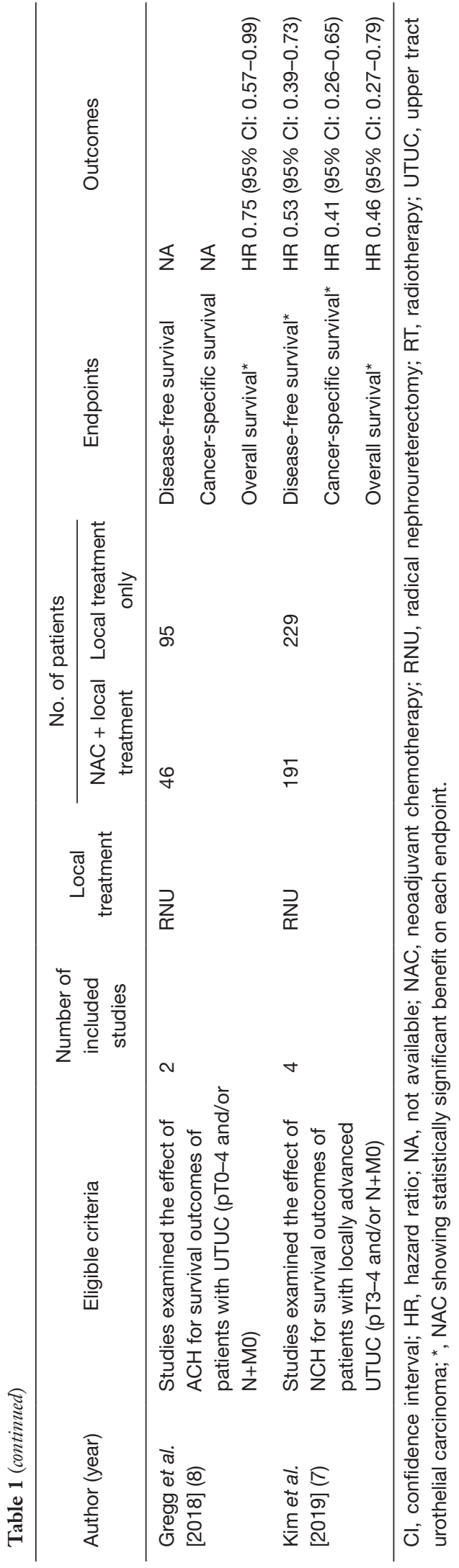

treatment for cisplatin-ineligible patients with progressive UC (41). Some studies showed that PD-L1 expression was related to poor prognosis in UC (42-45), whereas others did not detect a relationship between PD-L1 expression and prognosis (46-48). Therefore, further studies are needed to improve our comprehension of the prognostic importance of PD-L1 expression in UC to better choose patients who have a possibility to respond to the blocking agent for PD-1/PD-L1.

\section{Conclusions}

Our comprehensive review about the role of NAC in UTUC revealed that compared with surgery alone, NAC may have a beneficial effect on survival outcomes in patients with UTUC with a high risk of relapse. It is well known that the renal function is deteriorated after RNU, and if perioperative chemotherapy is considered for advanced UTUC, NAC may be a more reasonable option than adjuvant chemotherapy. Several meta-analyses demonstrated a beneficial effect of NAC on advanced UTUC; however, the level of evidence was relatively low; thus, careful interpretation is needed. Moreover, careful selection of NAC candidates is needed to avoid the possibility of overtreatment. Further trials are needed to identify the most suitable patients and validate the use of NAC in daily clinical practice. Recent immunotherapy data showed positive results for UCB, but there is a lack of data on immune checkpoint inhibitors in UTUC.

\section{Acknowledgments}

Funding: None.

\section{Footnote}

Provenance and Peer Review: This article was commissioned by the Guest Editors (Dr. Ja Hyeon Ku, Dr. Hyeong Dong Yuk, and Dr. Hyung Suk Kim) for the series "Urothelial Carcinoma" published in Translational Cancer Research. The article was sent for external peer review organized by the Guest Editors and the editorial office.

Conflicts of Interest: All authors have completed the ICMJE uniform disclosure form (available at http://dx.doi. org/10.21037/tcr.2020.03.08). The series "Urothelial Carcinoma" was commissioned by the editorial office without any funding or sponsorship. The authors have no 
other conflicts of interest to declare.

Ethical Statement: The authors are accountable for all aspects of the work in ensuring that questions related to the accuracy or integrity of any part of the work are appropriately investigated and resolved.

Open Access Statement: This is an Open Access article distributed in accordance with the Creative Commons Attribution-NonCommercial-NoDerivs 4.0 International License (CC BY-NC-ND 4.0), which permits the noncommercial replication and distribution of the article with the strict proviso that no changes or edits are made and the original work is properly cited (including links to both the formal publication through the relevant DOI and the license). See: https://creativecommons.org/licenses/by-nc-nd/4.0/.

\section{References}

1. Rouprêt M, Babjuk M, Comperat E, et al. European guidelines on upper tract urothelial carcinomas: 2013 update. Eur Urol 2013;63:1059-71.

2. Leow JJ, Chong KT, Chang SL, et al. Upper tract urothelial carcinoma: a different disease entity in terms of management. ESMO Open 2017;1:e000126.

3. Audenet F, Yates DR, Cussenot O, et al. The role of chemotherapy in the treatment of urothelial cell carcinoma of the upper urinary tract (UUT-UCC). Urol Oncol 2013;31:407-13.

4. Margulis V, Shariat SF, Matin SF, et al. Outcomes of radical nephroureterectomy: a series from the Upper Tract Urothelial Carcinoma Collaboration. Cancer 2009;115:1224-33.

5. Cornu JN, Roupret M, Carpentier X, et al. Oncologic control obtained after exclusive flexible ureteroscopic management of upper urinary tract urothelial cell carcinoma. World J Urol 2010;28:151-6.

6. Rouprêt M, Traxer O, Tligui M, et al. Upper urinary tract transitional cell carcinoma: recurrence rate after percutaneous endoscopic resection. Eur Urol 2007;51:70913; discussion 14.

7. Kim DK, Lee JY, Kim JW, et al. Effect of neoadjuvant chemotherapy on locally advanced upper tract urothelial carcinoma: A systematic review and meta-analysis. Crit Rev Oncol Hematol 2019;135:59-65.

8. Gregg RW, Vera-Badillo FE, Booth CM, et al. Perioperative chemotherapy for urothelial carcinoma of the upper urinary tract: A systematic review and metaanalysis. Crit Rev Oncol Hematol 2018;128:58-64.

9. Yagoda A. Chemotherapy of urothelial tract tumors. Cancer 1987;60:574-85.

10. Leow JJ, Martin-Doyle W, Fay AP, et al. A systematic review and meta-analysis of adjuvant and neoadjuvant chemotherapy for upper tract urothelial carcinoma. Eur Urol 2014;66:529-41.

11. Rouprêt M, Babjuk M, Comperat E, et al. European Association of Urology Guidelines on Upper Urinary Tract Urothelial Carcinoma: 2017 Update. Eur Urol 2018;73:111-22.

12. Browne BM, Stensland KD, Moynihan MJ, et al. An Analysis of Staging and Treatment Trends for Upper Tract Urothelial Carcinoma in the National Cancer Database. Clin Genitourin Cancer 2018;16:e743-50.

13. Cohen A, Kuchta K, Park S. Neoadjuvant and adjuvant chemotherapy use in upper tract urothelial carcinoma. Urol Oncol 2017;35:322-7.

14. Advanced Bladder Cancer (ABC) Meta-analysis Collaboration. Neoadjuvant chemotherapy in invasive bladder cancer: update of a systematic review and metaanalysis of individual patient data advanced bladder cancer (ABC) meta-analysis collaboration. Eur Urol 2005;48:2025; discussion 5-6.

15. Leow JJ, Martin-Doyle W, Rajagopal PS, et al. Adjuvant chemotherapy for invasive bladder cancer: a 2013 updated systematic review and meta-analysis of randomized trials. Eur Urol 2014;66:42-54.

16. Sternberg CN, Bellmunt J, Sonpavde G, et al. ICUDEAU International Consultation on Bladder Cancer 2012: chemotherapy for urothelial carcinoma-neoadjuvant and adjuvant settings. Eur Urol 2013;63:58-66.

17. Advanced Bladder Cancer (ABC) Meta-analysis Collaboration. Adjuvant chemotherapy in invasive bladder cancer: a systematic review and meta-analysis of individual patient data: Advanced Bladder Cancer (ABC) Meta-analysis Collaboration. Eur Urol 2005;48:189-199; discussion 199-201.

18. Spiess PE, Agarwal N, Bangs R, et al. Bladder Cancer, Version 5.2017, NCCN Clinical Practice Guidelines in Oncology. J Natl Compr Canc Netw 2017;15:1240-67.

19. Grossman HB, Natale RB, Tangen CM, et al. Neoadjuvant chemotherapy plus cystectomy compared with cystectomy alone for locally advanced bladder cancer. $\mathrm{N}$ Engl J Med 2003;349:859-66.

20. Kaag MG, O'Malley RL, O'Malley P, et al. Changes 
in renal function following nephroureterectomy may affect the use of perioperative chemotherapy. Eur Urol 2010;58:581-7.

21. Lane BR, Smith AK, Larson BT, et al. Chronic kidney disease after nephroureterectomy for upper tract urothelial carcinoma and implications for the administration of perioperative chemotherapy. Cancer 2010;116:2967-73.

22. Raman JD, Lin YK, Kaag M, et al. High rates of advanced disease, complications, and decline of renal function after radical nephroureterectomy. Urol Oncol 2014;32:47.e9-14.

23. Xylinas E, Rink M, Margulis V, et al. Impact of renal function on eligibility for chemotherapy and survival in patients who have undergone radical nephro-ureterectomy. BJU Int 2013;112:453-61.

24. Huang WC, Elkin EB, Levey AS, et al. Partial nephrectomy versus radical nephrectomy in patients with small renal tumors--is there a difference in mortality and cardiovascular outcomes? J Urol 2009;181:55-61; discussion 61-2.

25. Cutress ML, Stewart GD, Wells-Cole S, et al. Longterm endoscopic management of upper tract urothelial carcinoma: 20-year single-centre experience. BJU Int 2012;110:1608-17.

26. Huang WC, Levey AS, Serio AM, et al. Chronic kidney disease after nephrectomy in patients with renal cortical tumours: a retrospective cohort study. Lancet Oncol 2006;7:735-40.

27. Raman JD, Scherr DS. Management of patients with upper urinary tract transitional cell carcinoma. Nat Clin Pract Urol 2007;4:432-43.

28. McCarron JP, Mills C, Vaughn ED, Jr. Tumors of the renal pelvis and ureter: current concepts and management. Semin Urol 1983;1:75-81.

29. Matin SF, Kamat AM, Grossman HB. High-frequency endoluminal ultrasonography as an aid to the staging of upper tract urothelial carcinoma: imaging findings and pathologic correlation. J Ultrasound Med 2010;29:1277-84.

30. Liao RS, Gupta M, Schwen ZR, et al. Comparison of Pathological Stage in Patients Treated with and without Neoadjuvant Chemotherapy for High Risk Upper Tract Urothelial Carcinoma. J Urol 2018;200:68-73.

31. Siefker-Radtke AO, Dinney CP, Shen Y, et al. A phase 2 clinical trial of sequential neoadjuvant chemotherapy with ifosfamide, doxorubicin, and gemcitabine followed by cisplatin, gemcitabine, and ifosfamide in locally advanced urothelial cancer: final results. Cancer 2013;119:540-7.
32. Matin SF, Margulis V, Kamat A, et al. Incidence of downstaging and complete remission after neoadjuvant chemotherapy for high-risk upper tract transitional cell carcinoma. Cancer 2010;116:3127-34.

33. Yang X, Li P, Deng X, et al. Perioperative treatments for resected upper tract urothelial carcinoma: a network metaanalysis. Oncotarget 2017;8:3568-80.

34. Brown JA, Dorfman DM, Ma FR, et al. Blockade of programmed death-1 ligands on dendritic cells enhances $\mathrm{T}$ cell activation and cytokine production. J Immunol 2003;170:1257-66.

35. Garon EB, Rizvi NA, Hui R, et al. Pembrolizumab for the treatment of non-small-cell lung cancer. N Engl J Med 2015;372:2018-28.

36. Inman BA, Sebo TJ, Frigola X, et al. PD-L1 (B7-H1) expression by urothelial carcinoma of the bladder and BCG-induced granulomata: associations with localized stage progression. Cancer 2007;109:1499-505.

37. Latchman Y, Wood CR, Chernova T, et al. PD-L2 is a second ligand for PD-1 and inhibits T cell activation. Nat Immunol 2001;2:261-8.

38. Motzer RJ, Escudier B, McDermott DF, et al. Nivolumab versus Everolimus in Advanced Renal-Cell Carcinoma. N Engl J Med 2015;373:1803-13.

39. Robert C, Long GV, Brady B, et al. Nivolumab in previously untreated melanoma without BRAF mutation. N Engl J Med 2015;372:320-30.

40. Rosenberg JE, Hoffman-Censits J, Powles T, et al. Atezolizumab in patients with locally advanced and metastatic urothelial carcinoma who have progressed following treatment with platinum-based chemotherapy: a single-arm, multicentre, phase 2 trial. Lancet 2016;387:1909-20.

41. Balar AV, Galsky MD, Rosenberg JE, et al. Atezolizumab as first-line treatment in cisplatin-ineligible patients with locally advanced and metastatic urothelial carcinoma: a single-arm, multicentre, phase 2 trial. Lancet 2017;389:67-76.

42. Boorjian SA, Sheinin Y, Crispen PL, et al. T-cell coregulatory molecule expression in urothelial cell carcinoma: clinicopathologic correlations and association with survival. Clin Cancer Res 2008;14:4800-8.

43. Nakanishi J, Wada Y, Matsumoto K, et al. Overexpression of B7-H1 (PD-L1) significantly associates with tumor grade and postoperative prognosis in human urothelial cancers. Cancer Immunol Immunother 2007;56:1173-82.

44. Pichler R, Heidegger I, Fritz J, et al. PD-L1 expression 
in bladder cancer and metastasis and its influence on oncologic outcome after cystectomy. Oncotarget 2017;8:66849-64.

45. Xylinas E, Robinson BD, Kluth LA, et al. Association of T-cell co-regulatory protein expression with clinical outcomes following radical cystectomy for urothelial carcinoma of the bladder. Eur J Surg Oncol 2014;40:121-7.

46. Bellmunt J, Mullane SA, Werner L, et al. Association of PD-L1 expression on tumor-infiltrating mononuclear cells and overall survival in patients with urothelial carcinoma. Ann Oncol 2015;26:812-7.

47. Erlmeier F, Seitz AK, Hatzichristodoulou G, et al. The Role of PD-L1 Expression and Intratumoral Lymphocytes in Response to Perioperative Chemotherapy for Urothelial Carcinoma. Bladder Cancer 2016;2:425-32.

48. Faraj SF, Munari E, Guner G, et al. Assessment of tumoral PD-L1 expression and intratumoral CD8+ T cells in urothelial carcinoma. Urology 2015;85:703.e1-6.
Cite this article as: Kim DK, Cho KS. Neoadjuvant chemotherapy for upper tract urothelial carcinoma. Transl Cancer Res 2020;9(10):6576-6582. doi: 10.21037/tcr.2020.03.08 